\title{
Coworker Networks in the Labour Market
}

\author{
Albrecht Glitz \\ Universitat Pompeu Fabra and Barcelona GSE
}

May 2013

\begin{abstract}
This paper studies the role coworker-based networks play for individual labour market outcomes. I analyse how the provision of labour market relevant information by former coworkers affects the employment probabilities and, if hired, the wages of male workers who have previously become unemployed as the result of an establishment closure. To identify the causal effect of an individual worker's network on labour market outcomes, I exploit exogenous variation in the strength of these networks that is due to the occurrence of mass-layoffs in the establishments of former coworkers. The empirical analysis is based on administrative data that comprise the universe of workers employed in Germany between 1980 and 2001. The results suggest a strong positive effect of a higher employment rate in a worker's network of former coworkers on his re-employment probability after displacement: a 10 percentage point increase in the prevailing employment rate in the network increases the re-employment probability by 7.5 percentage points. In contrast, there is no evidence of a statistically significant effect on wages.
\end{abstract}

Keywords: Networks, Labour Markets, Employment, Wages

JEL Classification: J63, J64

\footnotetext{
Correspondence: Albrecht Glitz, Universitat Pompeu Fabra and Barcelona GSE. E-mail: albrecht.glitz@upf.edu. Address: Departamento de Economía y Empresa, Universitat Pompeu Fabra, Ramon Trias Fargas 25-27, 08005 Barcelona, Spain. Tel.: +34 93542 2757. Fax: +34 93542 1746. I am greatly indebted to the IAB and, in particular, Marco Hafner for the support with the data. I would also like to thank Antonio Ciccone, Anna Piil Damm, Christian Dustmann, Lena Hensvik, Oskar Nordström Skans, Patrick Puhani, Oddbjørn Raaum and Uta Schönberg as well as seminar participants at various institutions and conferences for helpful comments and suggestions. Finally, I thank the Barcelona GSE Research Network, the Government of Catalonia, the Spanish Ministry of Science (Project No. ECO2008-06395-C05-01 and ECO2011-30323-C03-02), and the Spanish Ministry of Economy and Competitiveness, through the Severo Ochoa Programme for Centres of Excellence in R\&D (SEV-2011-0075) for their financial support.
} 


\section{Introduction}

In many economic situations, individuals do not act autonomously but as members of social networks. This observation has encouraged substantial theoretical and empirical research on such networks and their role in society. ${ }^{1}$ In the labour market, social networks are likely to play an important role, primarily by facilitating the exchange of information about potential job opportunities and by reducing uncertainty about workers' and firms' characteristics. In this context, one of the key questions of interest is whether and to what extent a worker's labour market outcomes are affected by the social network he or she is embedded in.

To answer this question, I take a novel approach to the definition of networks in the labour market context. Using data describing the entire work histories of the universe of workers in four large metropolitan areas in Germany, I define a given worker's network as the group of all coworkers with whom he worked together in the same establishment at some point during the previous five years. The focus on former coworkers is motivated by the observation that in many cases in which a worker finds a job through a social contact, this contact is work-related. For example, in Granovetter's famous study of the job search behaviour of professional, technical and managerial workers in Boston (Granovetter, 1995), 69 percent out of the 56 percent of workers who found their job through a personal contact indicated that the contact was known from a work situation (compared to only 31 percent who indicated that the contact was a relative or friend). ${ }^{2}$ In addition, coworkers are likely to possess good knowledge of the specific abilities of a given worker and are more aware of potential job openings than, for example, neighbours, friends or family members who, although wanting to help, often lack the attachment to the relevant labour market segment (see Antoninis, 2006). Both these properties should make coworkers particularly valuable social contacts when looking for a new job. Finally, and in

\footnotetext{
${ }^{1}$ For overviews of the theoretical literature on social networks, see, for example, Goyal (2007) or Jackson (2008). Environments in which the role of social networks has recently been studied empirically include schools (e.g. Cipollone and Rosolia, 2007, or Calvó-Armengol et al., 2009), universities (e.g. DeGiorgi et al., 2010), individual establishments (e.g. Bandiera et al., 2009, or Mas and Moretti, 2009), and sports (Guryan et al., 2009). Outcomes that have been studied include social program participation (e.g. Dahl et al., 2012), the use of health services (Figlio et al., 2011), labour supply (Lalive and Parrotta, 2011), retirement (Duflo and Saez, 2003), criminal activity (e.g. Liu et al., 2012), and engagement in risky behaviour (Card and Giuliano, 2011).

${ }^{2}$ In the 2009/2010 National Educational Panel Study (NEPS) for Germany, 34 percent of respondents name former colleagues as a likely source of information about a job vacancy.
} 
contrast to most other network definitions, coworkers in the same establishment typically know each other. This is not trivial since in many studies of network effects actual personal contact between individual network members, a prerequisite for a network-based exchange of information, is not self-evident.

In the empirical analysis of this paper, I examine in detail the role coworker-based networks play for individual labour market outcomes, focussing on a sample of male workers who were displaced from their jobs as the result of an establishment closure. In the main specification, I study how the prevailing employment rate in a displaced worker's network of former coworkers at the time of displacement affects his re-employment probability and wage rate in the year after displacement. To account for unobserved group level shocks and potential sorting into networks based on observable and unobservable characteristics, I include a comprehensive set of control variables that capture a worker's permanent characteristics and past employment history, as well as a full set of fixed effects for the closing establishments, hence comparing the post-displacement labour market outcomes of workers who are displaced from the same establishment. However, since variation in these workers' networks (and their employment rates) arises from different past work histories, it may still be that a relationship between the network employment rate and a worker's own post-displacement outcomes is due to unobserved factors shared between members of the same network rather than the exchange of job-relevant information through the network. To deal with this problem, I employ a novel instrumental variable strategy that exploits past mass-layoffs as exogenous shocks to the employment rate in a worker's network. After separating from each other, some of a displaced worker's former coworkers may themselves become unemployed as the result of a mass-layoff. Under the assumption that, conditional on observable characteristics, the extent to which a coworker network is affected by such mass-layoffs is exogenous to any unobserved factors determining a worker's post-displacement outcomes, mass-layoffs can serve as a valid instrument for the prevailing employment rate in a network.

My empirical results show that coworker-based networks are an important feature of the labour market. Being embedded in a stronger network has a positive effect on the employment probability in the year after displacement but no effect on starting wages in the new job. According to results from the main specification, a 10 percentage point 
increase in the employment rate of a worker's network of former coworkers at the time of displacement increases the re-employment probability in the following year by 7.5 percentage points. This effect is robust to the inclusion of establishment/education group fixed effects as well as a large number of additional robustness checks. A number of placebo estimations provide suggestive evidence for the exogeneity of the instrumental variable by showing that contemporaneous mass-layoffs are unrelated to past labour market outcomes and that future mass-layoffs are unrelated to current labour market outcomes. Although statistically inconclusive, there is some indication that low-educated workers, immigrant workers, young workers, and workers employed in medium-sized firms benefit relatively more from increases in the employment rate in their networks. Among the group of former coworkers, female coworkers, coworkers from the same age cohort as the displaced workers, and coworkers with whom prior interaction was more intensive are particularly important for post-displacement employment outcomes. Finally, an analysis looking at the longer run effects reveals that the positive impact on the employment probability of a displaced worker only persists for the first year after displacement.

This analysis contributes to the growing empirical literature on the role of social networks in the labour market. In this literature, most studies exploit survey data and directly examine how the use of informal hiring methods is related to workers' labour market outcomes. ${ }^{3}$ While the evidence is not unambiguous, a majority of studies suggest a positive role of informal job finding methods for workers' labour market outcomes. In the absence of direct survey information on job finding methods and social interactions, an alternative set of empirical studies have employed a variety of network definitions likely to proxy for such interactions to indirectly test for the presence of network effects in the labour market. These network definitions comprise such diverse social groups as neighbours (e.g. Topa, 2001, Weinberg et al., 2004, Bayer et al., 2008, Schmutte, 2010, Hellerstein et al., 2011, Damm, 2012), individuals with the same (ethnic) origin (e.g. Munshi, 2003, Edin et al., 2003, Dustmann et al., 2011, Beaman, 2012), close friends (Cappellari and Tatsiramos, 2010), family members (Kramarz and Skans, 2011), freshmen

\footnotetext{
${ }^{3}$ Recent examples of such studies are Weber and Mahringer (2008) for Austria, Goel and Lang (2010) for Canada, Caliendo et al. (2011) for Germany, Frijters et al. (2005) for the UK, Kugler (2003), Loury (2006), and Brown et al. (2012) for the US, Pellizzari (2010) for a selection of European countries, and Bentolila et al. (2010) for both the US and Europe. For a comprehensive summary of the literature on the use of referrals in the labour market, see Ioannides and Loury (2004) and Topa (2011).
} 
hallmates (Marmaros and Sacerdote, 2002), and fellow war veterans (Laschever, 2009). The overall evidence from these studies, which typically relate the employment status of a worker to the prevailing employment rate in his network, points towards a positive role of social networks in the labour market. The only other existing study that explicitly analyses coworker-based networks is the work by Cingano and Rosolia (2012) who use a comparable empirical set-up as the present study but employ a different identification strategy to study the response of unemployment duration to the employment rate and size of a worker's group of former coworkers in two Italian provinces. ${ }^{4}$

The remainder of the paper is organised as follows. In the next section, I sketch the theoretical framework underlying the empirical analysis, show its empirical implementation, and explain the identification strategy. Section 3 describes the data source and sample preparation, and provides descriptive evidence on the main features of coworkerbased networks in Germany. Section 4 presents the empirical results, including robustness and placebo tests, as well as heterogeneity results for different subgroups of workers and former coworkers. Section 5 concludes.

\section{Empirical Strategy}

\subsection{Main Estimation Equation}

The empirical analysis in this paper builds on a theoretical framework in which the primary role of social networks in the labour market is to increase the arrival rate of job offers (see, for example, Montgomery, 1992, Calvó-Armengol and Jackson, 2004, 2007, Wahba and Zenou, 2005, Bramoullé and Saint-Paul, 2010, and Galeotti and Merlino, 2010). ${ }^{5}$ The basic information transmission process can be summarized as follows. In the first phase of each period, agents hear about a new job opportunity and the wage associated with it with an exogenous probability. If the agent is unemployed, he will

\footnotetext{
${ }^{4}$ To test Montgomery's (1991) employee referral model, a recent study by Hensvik and Skans (2012) also studies networks based on previous coworker relationships using Swedish matched employer-employee data.

${ }^{5}$ Alternatively, social networks may connect unemployed workers with potential employers by means of referrals, providing information about job match quality that both parties would otherwise not have (see, for example, the referral models by Montgomery, 1991, and Simon and Warner, 1992).
} 
accept the job. If the agent is employed and the new wage offer does not dominate the agent's current wage, he will pass the information about the new job on to one (or several) of his unemployed contacts. If an unemployed contact receives more than one job offer, he will accept the one that offers the highest wage. Given this type of information flow, unemployed agents who are embedded in a large and strong network characterised by a high employment rate should be more likely to find a new job and should receive higher wages than agents embedded in a small and weak network characterised by a low employment rate. ${ }^{6}$

Testing the main predictions of this model requires, in a first step, a definition of what constitutes a network and based on which criteria two agents can be considered connected. The central assumption in this paper is that two workers are directly connected if and only if both workers worked together in the same establishment at some point in the past five years, during the so-called network building phase.

To estimate the causal effect of the prevailing employment rate in a worker's network on his labour market outcomes, I focus on a setting that provides a natural starting point to study this relationship: establishment closures that push groups of workers from the same establishments into unemployment and onto the job market. Relative to more general job transitions, focussing on establishment closures as a source of job loss has the advantage of restricting the analysis to comparable workers who come out of the same set of establishments and who simultaneously start using their social networks in order to look for a new job, ruling out potential selection bias due to differential on-the-job search behaviour of workers with different network characteristics. ${ }^{7}$ The specific prediction that arises in this set-up is that displaced workers embedded in a large network with a high employment rate at the time of the establishment closure should be more likely to find a new job and earn higher wages in this job than displaced workers embedded in a small network with a low employment rate.

\footnotetext{
${ }^{6}$ Note that the unambiguous prediction regarding the exit rate from unemployment is based on the assumption that an unemployed worker accepts any job offer. Workers, however, may increase their reservation wage in response to an increase in their job offer arrival rate, so that the net effect on unemployment duration is a priori ambiguous. However, under standard assumptions regarding the shape of the wage offer distribution, the relationship between the exit rate from unemployment and the job offer arrival rate is non-negative (see van den Berg, 1994).

${ }^{7}$ For a similar strategy, see Dustmann and Meghir (2005) who use workers displaced due to firm closures to estimate returns to experience, sector-specific tenure and firm-specific tenure.
} 
To test these predictions, I estimate the following model:

$$
y_{i t+1}=\alpha+\beta_{1} E R_{i t}+\beta_{2} \log N S_{i t}+\gamma^{\prime} \mathbf{x}_{i t}+\varepsilon_{i t}
$$

where $E R_{i t}$ and $N S_{i t}$ represent the employment rate and network size of displaced worker $i$ 's network of former coworkers at the time of displacement $t$, and $\mathbf{x}_{i t}$ is a comprehensive set of both individual and average network characteristics. ${ }^{8}$ The dependent variable $y_{i t+1}$ is either an indicator variable taking the value one if a worker is observed working in the year after the establishment closure, or the log daily wage in the new job.

\subsection{Identification}

As is well known in the literature on social interaction effects, identification of the parameters of interest can be difficult because of the potential endogeneity of the network employment rate and size regressors in Equation (1) (e.g. Moffitt, 2001). ${ }^{9}$ In the present context, such endogeneity could arise as a result of common unobserved group level shocks that affect the outcomes of all workers who formerly worked together. It could also be the result of correlated unobservables due to either workers' sorting into particular establishments based on unobservable characteristics or common latent skills that were accumulated when workers worked together in the same establishment. For example, under sorting of more able workers into the same establishments, workers with high unobserved ability will tend to have a network consisting of other high ability workers,

\footnotetext{
${ }^{8}$ Individual characteristics included are a worker's educational attainment, potential experience and its square, immigrant status, tenure in the closing establishment, and the last log wage observed in the closing establishment. In addition, the following individual characteristics describing a worker's employment history during the network building phase are included: the modal 3-digit industry in which the displaced worker worked, the number of years employed, the average annual wage growth, the average establishment size, and the number of distinct employers during the network building phase. Network characteristics included are the average age of all former coworkers and its square, the share of former coworkers with medium and high educational attainment, the share of former coworkers that are women, and the share of former coworkers that are immigrants.

${ }^{9}$ Note that the reflection problem (Manski, 1993) often encountered when estimating linear-in-means models such as Equation (1) does not constitute a problem in the present context, since the groups of former coworkers generally differ across displaced workers due to the latter's heterogenous employment histories (see Bramoullé et al., 2009, and DeGiorgi et al., 2010). Within a given closing establishment, on average $72.9 \%$ of displaced workers used in the empirical analysis have a unique coworker network in terms of its employment rate and size. For a comprehensive treatment of identification in the context of social interactions, see Blume et al. (2011).
} 
potentially leading to a spurious positive correlation between the outcomes of the displaced worker and the employment rate prevailing in his network. On the other hand, more able workers are likely to have worked in larger establishments and, thus, will tend to have a larger network size. Both the employment rate and the network size regressors in Equation (1) are therefore potentially endogenous, leading to biased OLS estimates of both $\beta_{1}$ and $\beta_{2}$. The direction of the biases is a priori undetermined and depends on the correlations between the regressors and the unobserved error term $\varepsilon_{i t}$, as well as their correlation with each other. ${ }^{10}$

To overcome these issues, I include, in a first step, fixed effects for the closing establishments in the estimation of Equation (1) which account for any unobserved shocks at the time of displacement that may be specific to the workers of a given establishment. Identification is then coming from variation in the employment rate and size of the coworker networks across workers who are being displaced from the same establishment. To account for additional unobserved heterogeneity on the individual level, I further include a large set of individual control variables, among them the last wage observed before displacement, the number of years employed, the average annual wage growth, and the number of distinct employers during the network building phase.

However, even after conditioning on establishment fixed effects and a comprehensive set of control variables, it may still be that the relationship between a worker's outcomes and the employment rate and size of his network is a reflection of common latent skills shared by these workers. To deal with this issue, I exploit the occurrence of masslayoffs as exogenous shocks to the employment rate in a network. Suppose a displaced worker's network at the time of displacement consists of $N S_{i t}$ coworkers with whom he had worked during the network building phase. After separating from each other, some of these former coworkers may themselves have been part of a mass-layoff. ${ }^{11}$ Under the assumption that these mass-layoffs are unrelated to the displaced workers' unobserved

\footnotetext{
${ }^{10}$ Consider a simplified version of the empirical model in Equation (1): $y_{i}=\alpha+\beta_{1} E R_{i}+\beta_{2} N S_{i}+\varepsilon_{i}$. The asymptotic OLS bias of $\widehat{\beta}_{1}$ can be shown to be $\operatorname{plim}_{N \rightarrow \infty}\left(\widehat{\beta}_{1}^{O L S}-\beta_{1}\right)=\frac{\sigma_{N S}^{2} \sigma_{\varepsilon, E R}-\sigma_{N S, E R} \sigma_{\varepsilon, N S}}{\sigma_{N S}^{2} \sigma_{E R}^{2}-\sigma_{N S, E R}^{2}}$ where $\sigma_{N S}^{2}=\operatorname{Var}\left(N S_{i}\right)$ and $\sigma_{\varepsilon, N S}=\operatorname{Cov}\left(\varepsilon_{i}, N S_{i}\right)$, and $\sigma_{E R}^{2}, \sigma_{\varepsilon, E R}$ and $\sigma_{N S, E R}$ are defined analogously (see, for example, Frölich, 2008). Since the denominator of the right-hand side term is positive, the sign of the bias is determined by the sign of the difference in the numerator. Note that the partial correlation between the employment rate and the network size variables in the data $\left(\sigma_{N S, E R}\right)$ is 0.168 .

${ }^{11}$ Following the literature, I define a mass-layoff to occur if a large establishment's workforce declines by at least 30 percent from one year to the next (see, for example, Jacobson et al., 1993, or von Wachter et al., 2009).
} 
skill sets, they can serve as exogenous shocks to a given worker's network of coworkers. Following this reasoning, I construct for each displaced worker a measure of the share of his former coworkers who were themselves part of a mass-layoff after separating from the displaced worker. I then use this share as an instrument for the network employment rate $E R_{i t}$ in Equation (1).

More precisely, let $E_{i t-s}$ be the number of former coworkers who are employed in year $t-s$, and let $M_{i t-s}$ be the number of these coworkers who, after separation from displaced worker $i$, were in that year part of a mass-layoff in a large establishment with more than 50 employees. Then, letting $t$ denote the year of the establishment closure, the instrumental variable is calculated as

$$
Z_{i t}=\sum_{s=1}^{5} \frac{M_{i t-s}}{E_{i t-s}} .
$$

In the construction of the instrument, I use the number of working coworkers in the denominator rather than their overall number to avoid any variation in the instrument stemming from differences in the number of former coworkers who are employed (and thus at the risk of being laid off). Furthermore, I focus on mass-layoffs in large establishments as these are more likely to represent exogenous shocks. Finally, I ensure that in the rare cases in which a given coworker experiences more than one mass-layoff after separation, only the last layoff is counted. ${ }^{12}$

The identifying assumption required to obtain a consistent estimate of the parameter $\beta_{1}$ is that, conditional on the set of control variables (including the network size), the unobserved error term is mean independent of the instrument, $E\left[\varepsilon_{i t} \mid Z_{i t}, N S_{i t}, \mathbf{x}_{\mathbf{i t}}\right]=$ $E\left[\varepsilon_{i t} \mid, N S_{i t}, \mathbf{x}_{\mathbf{i t}}\right] .{ }^{13}$ In Section 4.1.2, I provide evidence in support of this assumption by means of a series of placebo tests in which I relate contemporaneous values of the instrument to past labour market outcomes and future values of the instrument to contempo-

\footnotetext{
${ }^{12}$ The empirical results are robust to alternative ways of constructing the instrument, such as $\sum_{s=1}^{5} M_{i t-s} / \sum_{s=1}^{5} E_{i t-s}$, or $\sum_{s=1}^{5} M_{i t-s} / \sum_{s=1}^{5} L_{i t-s}$, where $L_{i t-s}$ is the number of former coworkers employed in large establishments in period $t-s$.

${ }^{13}$ Considering again the simplified version of the empirical model, the asymptotic bias of the IV estimator of $\widehat{\beta}_{1}$ can be shown to be $\operatorname{plim}_{N \rightarrow \infty}\left(\widehat{\beta}_{1}^{I V}-\beta_{1}\right)=\frac{\sigma_{N S}^{2} \sigma_{\varepsilon, Z}-\sigma_{N S, Z} \sigma_{\varepsilon, N S}}{\sigma_{N S}^{2} \sigma_{E R, Z}-\sigma_{N S, E R} \sigma_{N S, Z}}$. Under the conditional mean independence assumption and the additional assumption that the error term is linear in the set of control variables, so that $E\left[\varepsilon_{i} \mid N S_{i}\right]=\theta+\gamma N S_{i}$, the instrumental variable estimate $\widehat{\beta}_{1}^{I V}$ will be consistent since $\sigma_{\varepsilon, Z}=\gamma \sigma_{N S, Z}$ and $\sigma_{\varepsilon, N S}=\gamma \sigma_{N S}^{2}$.
} 
raneous labour market outcomes. Note that in the absence of an additional instrument, the network size variable $\log \left(N S_{i t}\right)$ only serves as a control variable in the estimation and that $\widehat{\beta}_{2}$ therefore has no causal interpretation. Much of the discussion of the empirical results will thus focus on $\widehat{\beta}_{1}$, which measures the effect of a network's employment rate on a displaced worker's labour market outcomes, holding the overall network size constant.

In addition to addressing endogeneity issues, the use of mass-layoffs as an instrumental variable also deals with potential concerns about measurement error in the employment rate of a displaced worker's network of former coworkers. Such measurement error could arise because a displaced worker only maintains active links with an unobserved subset of former coworkers. If this subset was randomly drawn from the overall group of former coworkers (and abstracting from any endogeneity issues), the OLS estimate of $\widehat{\beta}_{1}$ would be consistent but less precisely estimated than in the absence of measurement error. On the other hand, if displaced workers maintain active links with a non-random subset of their former coworkers, the resulting measurement error in the employment rate of the relevant network will lead to inconsistent OLS estimates of $\widehat{\beta}_{1} \cdot{ }^{14}$ For example, if workers are only able to maintain a limited number of connections and selectively choose the "best" coworkers out of their overall pool of former coworkers, then, under reasonable assumptions regarding the distribution of observed employment rates, $\widehat{\beta}_{1}$ would be biased towards zero. ${ }^{15}$ Under the assumption that the share of coworkers who were part of a mass-layoff is uncorrelated with the measurement error, instrumental variable estimation of Equation (1) will yield consistent estimates of $\widehat{\beta}_{1}$.

\footnotetext{
${ }^{14}$ To see this, suppose the true model is given by $y_{i}=\alpha+\beta_{1} E R_{i}^{*}+\varepsilon_{i}$, where $E R_{i}^{*}$ is the employment rate prevailing among the set of coworkers with whom displaced worker $i$ maintains active links. Let $E R_{i}^{*}=\theta+E R_{i}+u_{i}$, where $E R_{i}$ is the observed employment rate among all former coworkers. Then $\operatorname{plim}_{N \rightarrow \infty} \widehat{\beta}_{1}^{O L S}=\beta_{1} \frac{\sigma_{E R}^{2}+\sigma_{u, E R}}{\sigma_{E R}^{2}}$, where $\sigma_{E R}^{2}=\operatorname{Var}\left(E R_{i}\right)$ and $\sigma_{u, E R}=\operatorname{Cov}\left(u_{i}, E R_{i}\right)$. Thus, if displaced workers maintain links with a random subset of their former coworkers, $\sigma_{u, E R}=0$ and $\operatorname{plim}_{N \rightarrow \infty} \widehat{\beta}_{1}^{O L S}=$ $\beta_{1}$. On the other hand, if $\sigma_{u, E R} \neq 0, \widehat{\beta}_{1}^{O L S}$ will be inconsistent.

${ }^{15}$ To illustrate this point, consider two displaced workers, each with a network of ten former coworkers, and assume these workers can only maintain at most six links at a time. Suppose we observe employment rates of $50 \%$ for Worker A and $100 \%$ for Worker B. Now, if both workers only maintain active links with the six "best" coworkers out of their pool of 10 candidates, the true employment rate in Worker A's network is $83.3 \%$ (5/6) while the true employment rate in Worker B's network is still $100 \%$. Estimation based on the observed employment rates will then lead to a downward biased estimate of the effect of the network's employment rate on a displaced worker's outcomes. Note, that in this setting, the direction of the bias (the sign of $\sigma_{u, E R}$ ) depends on the distribution of observed employment rates in the sample and the share of (positively selected) contacts that can be maintained.
} 


\section{$3 \quad$ Data and Descriptives}

The data used in the analysis derive from administrative records and comprise the universe of workers in Germany who are subject to social security contributions. ${ }^{16}$ The observations in the sample are recorded annually on the $30^{\text {th }}$ of June, and span more than two decades, from 1980 to 2001. Each record contains a unique worker and establishment identifier as well as information about a wide array of a worker's background characteristics, such as education ${ }^{17}$, occupation, industry, and citizenship. From this data base, I construct a panel data set of all establishments operating in one of the four largest metropolitan areas in Germany: Hamburg, Cologne, Frankfurt, and Munich. ${ }^{18}$

The base years for my analysis are the years 1995 and $1996{ }^{19}$ I obtain a list of all establishments that exist in those years but do not exist anymore in the following year (8.7 percent of all active establishments). From this set of establishments, I select those that had between 5 and 50 workers in the last year of business (13.2 percent of the sample of closing establishments) and for whom the maximum share of displaced workers who end up working together in another establishment in the year after the establishment closure is smaller than 50 percent, leaving a total of 1,814 establishments in the sample. ${ }^{20}$

In the next step, I collect information about all male workers who are working in these establishments in their last year of existence and who have been present in the German labour market during the entire network building phase. ${ }^{21}$ These constitute the sample

\footnotetext{
${ }^{16}$ In 2001, $77.2 \%$ of all workers in the German economy were covered by social security and are hence recorded in the data (Bundesagentur für Arbeit, 2004). The main groups not included in the data are civil servants, the self-employed, and military personnel.

${ }^{17}$ To improve the consistency of the education variable, I apply the imputation algorithm suggested by Fitzenberger et al. (2006).

${ }^{18}$ These metropolitan areas are relatively large, covering, on average, an area of around 2,150 square miles and a population of 2.9 million individuals in 1995, distributed over, on average, 8 counties (Kreise) and 200 municipalities (Gemeinden). I do not include Berlin which is a special case due to German unification in 1990.

${ }^{19}$ The motivation for choosing these particular years it that they provide a sufficiently long pre- and post-displacement period which allows controlling for the labour market histories of the workers as well as studying longer-run effects.

${ }^{20}$ The motivation for this sample selection is the following. I exclude very small establishments since these are often family-run and provide insufficient variation in network structure within establishments. I exclude establishments whose majority of the workforce continuous to work together in a new establishment after the closure to avoid including establishments that simply change their legal status, for example through mergers or takeovers, in which case they would receive new identifiers and hence appear as new establishments in the data (for a similar procedure, compare Schmieder et al., 2009).

${ }^{21}$ In practice, this means that a worker must have been observed for the first time in the data at the latest in the first year of the network building phase, $t-5$. This restriction ensures a better comparability of co-displaced workers with respect to their network characteristics.
} 
of displaced workers. I focus on male workers as these are more likely to remain attached to the labour market and try to find a new job after displacement. For each displaced worker, I then collect information on all other workers he has ever worked with in the same establishment. ${ }^{22}$

For the construction of the network-related variables, I only consider those coworkers who worked together with a given displaced worker during the network building phase, defined as the 5-year period prior to the corresponding base year, but not including it. So, for example, the network building phase for those workers who were displaced in 1995 extends from 1990 to 1994 . Consequently, other contemporaneously displaced workers are not included in the set of coworkers. ${ }^{23}$ The motivation for this restriction is that these workers become unemployed at the same time as the displaced worker and should therefore be unable to provide any information about new job opportunities. I restrict the network building phase to the preceding five years based on the assumption that the strength of a link between two workers depreciates over time: any link between two workers that was last active more than 5 years ago (by means of working together in the same establishment) has ceased to provide any information to the displaced worker in the year of displacement. Finally, I trim the estimation sample by dropping those displaced workers with a network size above the 95 th percentile. ${ }^{24}$

Table 1 shows descriptive statistics for the sample of displaced male workers. Overall, there are 10,916 workers who become unemployed as the result of 1,814 establishment closures in the Hamburg, Cologne, Frankfurt and Munich metropolitan areas in 1995 and 1996. Around 13.8 percent of these workers are foreign citizens. Most of the displaced workers in the sample have medium education which in the German context refers to vocational training. Around 10.8 percent do not have vocational training or have missing information about their educational attainment, and about 8.2 percent of workers have university education. In terms of sectoral composition, large numbers of displaced work-

\footnotetext{
${ }^{22}$ Note that while the sample only includes closing establishments in the Hamburg, Cologne, Frankfurt, and Munich areas, the construction of the network and employment history variables is based on prior jobs in all of Germany.

${ }^{23}$ On average, $30.1 \%$ of all coworkers a displaced worker worked with during the network building phase and the displacement year are also co-displaced workers.

${ }^{24}$ The distribution of network sizes across displaced workers is strongly right-skewed, with a median of 48 , a mean of 508 and a 95 th percentile of 1,416 former coworkers. The trimming of the data avoids results being driven by extreme outliers in the network size variable. However, the empirical results are also robust to using the full sample of displaced workers.
} 
ers worked in basic manufacturing, construction, and professional, medical and business services in their last job.

Table 2 provides information about some key summary statistics for the period before the establishment closure (top panel), the year after the establishment closure (middle panel), and the instrumental variable (bottom panel). During the network building phase, the average number of distinct coworkers a displaced worker worked with was 133 . This average figure conceals the fact that the (trimmed) network size distribution is strongly right-skewed, with a 10 th percentile of 9 , a median of 43 , and a 90 th percentile of 379 . The average employment rate in the networks of former coworkers in the years of displacement - the main variable of interest in the empirical analysis - is 58.4 percent with a standard deviation of 18.0 percent, varying between 35.1 percent at the 10th percentile and 79.1 percent at the 90th percentile. On average, a displaced worker worked 3.0 years with his former coworkers although there is substantial variation, reaching from one year at the 10th percentile to 7 years at the 90th percentile. Between 1980 and 1995/1996, the average displaced worker was employed for about 12.4 years, working in 3.5 different establishments and spending around 3.4 years in each of them. The average tenure in the establishment that eventually closes down in either 1995 or 1996 is somewhat larger, about 5.1 years. The average daily wage earned in the closing establishments is around 88.1 euros. $^{25}$ During the 5 -year long network building phase, displaced workers are observed working 4.4 years in, on average, 2.1 distinct establishments with typically around 64.8 employees. Finally, the median annual wage growth during the network building phase is 1.7 percent. $^{26}$

The middle panel of Table 2 shows workers' employment and wage outcomes in the first year after their displacement. Overall, 71.6 percent of displaced workers are working again in the year after displacement, earning, on average, a daily wage of 87.6 euros which is about the same as the average wage in the sample prior to displacement.

The bottom panel of Table 2 provides some summary statistics for the instrumental

\footnotetext{
${ }^{25}$ Wage records are right-censored at the social security contribution ceiling, which affects 6.4 percent of observations in 1995/1996. I impute these wages by first estimating a tobit model with a standard set of socio-economic wage determinants (gender, citizenship, education, region and industry) and then adding a random error term to the predicted value of each censored observation, ensuring that the imputed wage lies above the censoring threshold (see Gartner, 2004, for details). I proceed correspondingly for all censored wage observations in later years of the sample.

${ }^{26}$ This high average rate of annual wage growth of 26.7 percent is driven by a few extreme outliers.
} 
variable used in the analysis. On average, 4.2 percent of a displaced worker's working former coworkers were laid off from an establishment with more than 50 employees after they separated from the displaced worker. As indicated by the standard deviation of 10.9 percent, there is some variation in this share across displaced workers, reaching from 0 percent at the 10th percentile to 10.0 percent at the 90th percentile (and 21.2 percent at the 95th percentile). In the second row in the bottom panel, I eliminate variation in the average share of laid-off coworkers that exists between different closing establishments by regressing these shares on a full set of fixed effects for the closing establishments and then summarizing the predicted residual shares. Importantly, the standard deviation only decreases by 17.4 percent to 9.0 percent, indicating that most of the variation in the instrumental variable exists within rather than between establishments. This is important because I control for establishment fixed effects in the analysis and rely on differential shocks to the networks of workers that belong to the same closing establishment. As the last row shows, even within groups of workers with the same education level who are being displaced from the same establishment, there is still variation in the share of laid-off coworkers. The relatively small loss in identifying variation after the inclusion of comprehensive sets of fixed effects provides some first suggestive evidence that these mass-layoffs may indeed be exogenous events.

\section{Empirical Results}

\subsection{Basic Results}

In this section, I investigate how the prevailing employment rate in a displaced worker's network of former coworkers affects his employment probability and wages one year after the displacement. As pointed out before, in the absence of a suitable instrument, I will view the network size variable simply as an additional control variable whose estimated impact on labour market outcomes can generally not be given a causal interpretation. The first three columns in Table 3 show the results of a linear probability model for being employed based on Equation (1). Column (1), which includes all the individual and average network characteristics but no establishment fixed effects, shows a small positive 
association between the employment rate in the network and the probability of being employed one year after displacement. ${ }^{27}$ Including a full set of fixed effects for the closing establishments in column (2) reduces the coefficient to a statistically not significant 0.051 . However, as discussed in Section 2, in the presence of measurement error or endogeneity of the employment rate and network size control variable, the estimated OLS parameters are likely to be biased. Column (3) shows the results when the networks' employment rates are instrumented with the shares of coworkers who were themselves part of a masslayoff after separation from the displaced workers. As the summary of the first stage regression at the bottom of the table shows, there is a strong negative effect of this share on a network's employment rate in the year of displacement: a 10 percentage point increase in the share of laid-off coworkers during the network building phase, reduces their employment rate in 1995/1996 by 1.3 percentage points. Exploiting the variation in employment rates that is driven by these mass-layoff shocks, the second-stage results indicate a strong positive effect of the network employment rate on the re-employment probability of a displaced worker: a 10 percentage point increase in the employment rate, which corresponds to about half a standard deviation (compare Table 2), leads to a 7.5 percentage point higher probability of being employed in the first year after displacement (p-value 0.052). ${ }^{28}$

Columns (4) to (6) in Table 3 show the corresponding results for the log wages in the new jobs of the displaced workers. While in the OLS regressions, there is some indication of a small positive association between the network employment rate and workers' starting wages, there is no evidence of a causal effect of a higher network employment rate on the starting wages after accounting for potential endogeneity and measurement error. The absence of a significant effect on starting wages can be rationalised within the theoretical framework laid out in Section 2 if workers do not adjust their reservation wages in response

\footnotetext{
${ }^{27}$ An unconditional OLS regression that only includes the network employment rate and the network size as regressors yields significant estimates of 0.118 (0.027) and 0.007 (0.004), respectively.

${ }^{28}$ This effect is larger in magnitude than the main estimate in the study by Cingano and Rosolia (2012), who, based on an OLS specification similar to that in column (2) of Table 3, find that a 10 percentage point increase in the network employment rate increases the probability of being employed 9 months after displacement by 1.8 percentage points. Since the German data are recorded annually, the duration between displacement and the first observed post-displacement period is typically less than one year; 6 months on average under the assumption that establishment closures are uniformly distributed over time. Linearly extrapolating the results for 12 and 9 months, separately reported in Cingano and Rosolia (2012), to a horizon of 6 months would imply a 2.4 percentage point higher employment probability in response to a 10 percentage point increase in the network employment rate.
} 
to changes in their job offer arrival rate due to shocks to their coworker networks, either because these changes are unanticipated or because workers do not expect them to be persistent. The absence of a causal effect of the network employment rate on entry wages also speaks against potential alternative mechanisms that could lead to a positive association between average network employment rates and individual-level employment probabilities, such as leisure complementarities (Jenkins and Osberg, 2004) or social norms (Akerlof, 1980, Stutzer and Lalive, 2004). If these channels were the main drivers of individuals' job search behaviour, workers with higher prevailing employment rates in their networks should set lower reservation wages in order to increase their chances of escaping unemployment, and thus end up working in lower-paid jobs.

As discussed in Section 2, the apparent downward bias of the OLS estimates relative to the IV estimates - in particular in the employment estimations - could be driven by the two network regressors' endogeneity and their correlation with each other, as well as measurement error in the network employment rate. However, it should also be pointed out that both estimates are likely to capture different types of effects. The IV estimate is based on variation in a network's employment rate due to mass-layoffs of workers whereas the variation for the OLS estimate is driven by more diverse determinants of workers' employment status, including retirement, health or family reasons. Since laidoff workers are presumably quite attached to the labour market, they are more likely to keep a job information to themselves rather than pass it on than, for example, retired former coworkers or former female coworkers on maternity leave. As a result, a given change in the network employment rate due to mass-layoffs is likely to have a bigger effect on an individual worker's labour market outcomes than a corresponding change due to alternative reasons.

\subsubsection{Robustness Checks}

Table 4 summarizes the results from a number of robustness checks for the main result of a positive effect of the employment rate in a worker's network on his re-employment probability. ${ }^{29}$ In column (1), I condition on establishment/education fixed effects rather than

\footnotetext{
${ }^{29}$ The corresponding results for the starting wages consistently show small and statistically not significant effects.
} 
just establishment fixed effects as in the baseline specification. By doing so, I compare the employment outcomes of workers who are displaced from the same establishment and who have the same education level prior to their displacement. This specification leads to an estimate of 0.658 ( $\mathrm{p}$-value 0.101 ), broadly comparable in magnitude to the baseline result of 0.753 (compare column (3) of Table 3).

Column (2) shows the results from an estimation without any worker- or networkspecific control variables (apart from network size and establishment fixed effects). Given that a number of control variables are highly statistically significant in the baseline IV regression, the fact that the point estimate on the network's employment rate hardly changes in the absence of these control variables indicates that the instrument is not systematically related to these observable characteristics, providing some suggestive evidence for its exogeneity.

Columns (3) and (4) present results for two alternative definitions of the instrumental variable. In column (3), I extend the range of establishments that are considered for the construction of the mass-layoff instrument to those with more than 10 employees (rather than using only large establishments with more than 50 employees). As these mass-layoffs occur more often, the first stage is substantially stronger. However, the point estimate of 0.601 is still similar in magnitude to the estimate in the baseline specification. In column (4), I exclude mass-layoffs that occurred in the year immediately prior to the base year from the construction of the instrument (so $Z_{i t}=\sum_{s=2}^{5}\left(M_{i t-s} / E_{i t-s}\right)$ ). This is because mass-layoffs may to some extent proxy for shocks in labour demand for particular groups of workers, and if these shocks show sufficient persistence, they could have a direct impact on a displaced worker's re-employment probability. Note, however, that for this to be problematic in the present setting, the direct impact would have to differ across workers who are being displaced from the same establishment. As the results in column (4) show, even with this more conservative definition of the instrument, the point estimate remains similar in magnitude to the baseline estimate (albeit not statistically significant). In column (5), I add the average log wage among the group of former coworkers at the time of displacement as a further control variable to capture an additional dimension of the quality of a displaced worker's network. Again, results remain largely unchanged.

According to the information transmission process outlined at the beginning of Sec- 
tion 2, employed agents forward any job information they do not need themselves to one of their unemployed contacts. From the perspective of a recently displaced worker, this implies that unemployed two-link away contacts - those workers who worked together with one of the former coworkers during the network building phase but never with the displaced worker himself - are competitors for available job information. In column (6), I include the employment rate and log number of each displaced worker's two-link away contacts as additional regressors, instrumenting the employment rate with the share that was part of a mass-layoff in a large establishment during the network building phase (constructed in the same way as for the direct contacts). Contrary to the theoretical prediction, the employment rate among the two-link away contacts has no effect on a displaced worker's probability of working in the year after displacement. Reassuringly, however, the point estimate of the coefficient for the employment rate of the direct contacts remains relatively unaffected, with a value of 0.677 (p-value 0.103).

Finally, in column(7), I check the robustness of my results to the functional form specification of the network size control variable. Rather than including the log number of coworkers, I include a quadratic function that allows for a non-monotonic relationship between network size and the re-employment probability of the displaced worker. In this case, the estimated parameter is slightly larger than in the baseline specification but still of comparable magnitude.

Overall, the results in Table 4 show a robust positive effect of the network employment rate on the re-employment probability of a displaced worker, with the baseline estimate of 0.753 being roughly the midpoint of the range of estimates obtained across the alternative specifications.

\subsubsection{Placebo Tests}

The identification of the causal effect of the network employment rate on a displaced worker's post-displacement labour market outcomes hinges upon the assumption that any unobserved individual-level characteristics that may affect these outcomes directly are conditionally (mean) independent of the instrument. To support the validity of this assumption, I carry out two placebo tests. In the first test, I replace the actual postdisplacement outcomes in my estimations with the corresponding outcomes observed prior 
to the network building phase. If mass-layoffs of a displaced worker's coworkers during the network building phase are exogenous events, they should be uncorrelated with any unobserved permanent individual characteristics that may affect labour market outcomes directly, and therefore uncorrelated with a displaced worker's past employment outcomes.

Columns (3) and (4) of Table 5 show the corresponding results, where the dependent variable is the displaced worker's employment status in 1989 (for displacement year 1995) and 1990 (for displacement year 1996). I report both the reduced form effect of the instrument, and the second-stage results from the standard IV estimation. For comparison, I report the corresponding estimates from the baseline specification (compare Table 3) in columns (1) and (2). Focussing on the reduced form first, column (3) shows that there is no significant relationship between the share of laid-off coworkers and the displaced worker's past employment probability, with an estimate of 0.017 which is close to zero and statistically not significant. The second-stage coefficient of -0.127 reported in column (4) is consequently also close to zero. ${ }^{30}$ For comparison, the reduced form coefficient from my baseline specification is -0.099 . Note that the corresponding OLS regression of past employment outcomes on current employment rates of coworkers yields a positive and significant estimate of $0.076(0.042)$, indicating that the latter are indeed likely to proxy for some unobserved worker characteristics.

In the second placebo test, I change the time period over which I construct the instrumental variable and estimate the relationship between a displaced worker's employment status in the year after displacement $(t+1)$ and the share of former coworkers displaced as the result of a mass-layoff during the subsequent period $t+1$ to $t+5$. Since these layoffs occur after the $t+1$ observation, they should have no effect on a displaced worker's labour market outcomes in that year, unless they reflect some unobserved individual characteristics of the displaced workers. ${ }^{31}$ The reduced form results in column (5) of Table 6 show a substantially smaller and not significant effect of future mass-layoffs on current outcomes and hence speak against the hypothesis that mass-layoffs of coworkers are simply a reflection of individual displaced workers' labour market prospects.

Overall, the results from the two placebo tests indicate that there is no relationship

\footnotetext{
${ }^{30}$ The corresponding placebo results for wages show effectively zero reduced form coefficients both in the benchmark case and for past wages, and hence small and insignificant second-stage coefficients.

${ }^{31}$ Note that if a given coworker is subject to more than one mass-layoff between $t+1$ and $t+5$, I use the earlier one for the construction of the instrumental variable.
} 
between either the instrumental variable and past labour market outcomes or between the future instrumental variable and current labour market outcomes of the displaced workers, lending support to the assumption that the underlying mass-layoffs are exogenous events and unrelated to unobserved worker characteristics.

\subsection{Heterogeneity Across Demographic Subgroups}

In this section, I investigate whether the impact of the network employment rate on the re-employment probability varies across subgroups of workers. Running separate regression after splitting the sample by educational attainment, nationality and age does not provide conclusive evidence as the large majority of observations happen to belong to one specific subgroup, workers with medium education level (81.0 percent of the sample), German workers (86.2 percent of the sample), and the group of prime-age males. Since all estimations include establishment fixed effects, there is relatively little variation for the smaller subgroups from which to estimate the effect of interest. Taken at face value, however, the point estimates reported in columns (1) to (8) of Table 6 suggest a stronger network effect for low-educated and young individuals as well as for immigrants, a finding supported by survey evidence and existing studies analysing the role of networks in the labour market (see Topa, 2011). ${ }^{32}$ Columns (9) to (11) show separate results based on the size of the closing establishments in the years of displacement. There seems to be a stronger effect for workers who are displaced from medium-sized establishments with an overall employment between 11 and 30 employees, but again, standard errors tend to be quite large owing to the reduced sample sizes, making any conclusive statements difficult.

\subsection{Heterogeneity Across Information Providers}

By focussing on the overall employment rate in a worker's network of former coworkers, I have so far implicitly assumed that each contact is equally likely to transmit labour market relevant information to the displaced workers. However, it is conceivable that

\footnotetext{
${ }^{32}$ According to the German Socio-Economic Panel, 38.6 percent of low-educated workers, 29.9 percent of medium-educated workers, 23.5 percent of high-educated workers, 41.8 percent of immigrant workers, 30.0 percent of German workers, 33.3 percent of young workers $(\leq 30)$, and 29.1 percent of older workers found their current job through acquaintances, friends and relatives. Data Source: GSOEP 1990-2001.
} 
some coworkers are better providers of job information than others, either because they are more likely to hear about relevant job offers or because they are more likely to forward this information to the displaced worker. Focussing on the latter aspect first, it is well known from sociological evidence that individuals tend to associate with other individuals who are similar in terms of socio-economic characteristics (e.g. McPherson et al., 2001). If such homophily is reflected in a higher propensity to exchange job information, the employment rate of coworkers who are similar to the displaced workers should have a larger effect on the latter's labour market outcomes than the employment rate of dissimilar coworkers. To test this prediction, I define similarity in terms of either age, gender, education or nationality, and split the overall employment rate in worker $i$ 's network at the time of displacement, $E R_{i t}=E_{i t} / N S_{i t}$, into the share of workers who are similar, $S_{i t} / N S_{i t}$, and the share of workers who are dissimilar, $D_{i t} / N S_{i t}$, in the characteristic in question, where $S_{i t}+D_{i t}=E_{i t}$. Table 7 reports the corresponding results. Column (1) shows that coworkers who are of the same age cohort (defined as within +/- five years of the displaced worker's age) have indeed a relatively larger effect on the re-employment probability of a displaced worker. In contrast, columns (2) to (4) suggest that female coworkers, coworkers with a different education level and coworkers of a different nationality have a stronger effect on a displaced worker's employment outcome after displacement. This may seem surprising. However, it is important to keep in mind that these differential effects between different groups of coworkers are derived conditional on having worked together at the same employer. It may well be that homophily in social interaction leads to a clustering of different groups of workers in certain establishments, but that once workers interacted with each other on a daily basis at the workplace, differences in education, gender or nationality are actually conducive to the exchange of information. Also, note that none of the differences in coefficients reported in columns (2) to (4) is statistically significantly different from zero.

In Table 8, I differentiate subgroups of coworkers in terms of their presumed ability to provide relevant information. In columns (1) and (2), I assess whether coworkers who most recently worked in the same three-digit industry and regional area (county), respectively, have a particularly strong effect on the re-employment probability of a displaced worker. Workers who have moved to a different industry than the one in which 
the displaced worker was last employed may be able to provide more novel information about job opportunities relative to workers who remain active in the same industry as the displaced worker. The significant difference of the coefficients in column (1) seems to support this hypothesis. On the other hand, workers who are still working in the same county as the displaced worker appear to be more valuable as a source of information, possibly because the displaced workers are primarily searching for new jobs in the geographical vicinity of their last job. In column (3), I distinguish coworkers based on the contact intensity they had with the displaced worker, using the duration of cowork as a proxy of such intensity. As expected, the effect of the group of coworkers with whom the displaced worker worked for more than the median duration in the sample is larger than for those with whom he worked less than the median duration. Finally, in column (4), I allow for the fact that a connection to a coworker that was established while working in a large establishment may be less strong than a connection to a coworker that was established during a joint employment spell in a small establishment, as workers may be constraint regarding the overall number of social contacts and the intensity with which they can maintain them. The results suggest that indeed contacts acquired in small establishments are more valuable than those acquired in large establishments, although for this estimation in particular, the estimated parameters are not statistically different from each other.

\subsection{Persistence of Effects}

Given the strong positive effect of the prevailing employment rate in a given worker's network on his employment probability in the year after displacement, it is interesting to investigate how persistent this effect is over time. For this reason, I estimate the baseline model separately for each of the five post-displacement years covered by the data. Table 9 shows the corresponding results, restating in column (1) the baseline result obtained for the first year after displacement (compare column (3) in Table 3). The profile of the estimated coefficients shows that the positive effect on a displaced worker's employment status declines rapidly over time. Already from the second post-displacement year onwards, there is no more discernable difference in the employment rates of workers who were part of a strong network at the time of displacement, and workers who were part 
of a weak network. This is maybe not too surprising given the expected strong labour market attachment of the sample of male workers in this study. The primary effect of coworker-based networks thus appears to be a more rapid transition out of unemployment rather than a persistent improvement of employment outcomes.

\section{Conclusion}

This paper diverges from much of the existing literature on the role of social networks in the labour market by focussing on networks of former coworkers. Coworkers are likely to play an important role in the exchange of labour market relevant information between individuals. As opposed to most other acquaintances, coworkers are likely to possess good knowledge of a given worker's specific skills and be more aware of job opportunities appropriate for the worker in question. Using data on the universe of workers in Germany, I show that the strength of a worker's network has a sizeable effect on the probability of finding a new job after being displaced as the result of an establishment closure. The empirical analysis systematically takes account of unobserved correlated group level effects and individual sorting into establishments, allowing a causal interpretation of the estimated effects. This is achieved through the inclusion of a comprehensive set of fixed effects and control variables, and, most importantly, the use of exogenous shocks to the networks in the form of mass-layoffs. According to the baseline specification, a 10 percentage point increase in the employment rate of a displaced worker's network of former coworkers increases the probability of finding a job in the year after displacement by 7.5 percentage points. In contrast, there is no evidence of a positive effect of a stronger network on the starting wages of workers, suggesting that workers do not adjust their reservation wages to unexpected changes in the rate at which job offers arrive through their networks. The positive employment effects are relatively short-lived, robust to changes in specification and alternative definitions of the key variables involved, and not driven by possible correlations between the instrument and unobserved characteristics of workers. Overall, the findings of this study suggest that a strong network of coworkers provides valuable information about labour market opportunities and can serve as a useful resource to accelerate transition out of unemployment in times of economic distress. More 
generally, the findings also imply that social networks act as amplifiers of economic shocks, which could partly explain the substantially larger employment response of, for instance, low skilled workers to business cycle fluctuations. 


\section{References}

Akerlof, G. A. (1980). A theory of social custom, of which unemployment may be one consequence. Quarterly Journal of Economics 94(4), 749775.

Antoninis, M. (2006). The wage effects from the use of personal contacts as hiring channels. Journal of Economic Behavior \& Organization 59(1), 133-146.

Bandiera, O., I. Barankay, and I. Rasul (2009). Social connections and incentives in the workplace: Evidence from personnel data. Econometrica 7r7(4), 1047-1094.

Bayer, P., S. E. Ross, and G. Topa (2008). Place ofwork and place of residence: Informal hiring networks and labor market outcomes. Journal of Political Economy 116(6), $1150-1196$.

Beaman, L. A. (2012). Social networks and the dynamics of labor market outcomes: Evidence from refugees resettled in the U.S. Review of Economic Studies, forthcoming.

Bentolila, S., C. Michelacci, and J. Suarez (2010). Social contacts and occupational choice. Economica $77(305), 20-45$.

Blume, L. E., W. A. Brock, S. N. Durlauf, and Y. M. Ioannides (2011). Identification of social interactions. In A. B. Jess Benhabib and M. O. Jackson (Eds.), Handbook of Social Economics, Volume 1, Chapter 25, pp. 853-964. Elsevier.

Bramoullé, Y., H. Djebbari, and B. Fortin (2009). Identification of peer effects through social networks. Journal of Econometrics 150(1), 41-55.

Bramoullé, Y. and G. Saint-Paul (2010). Social networks and labor market transitions. Labour Economics 17(1), 188-195.

Brown, M., E. Setren, and G. Topa (2012). Do informal referrals lead to better matches? Evidence from a firm's employee referral system. Working Paper.

Bundesagentur für Arbeit (2004). Arbeitsmarkt 2003. Amtliche Nachrichten der Bundesagentur für Arbeit. 
Caliendo, M., R. Schmidl, and A. Uhlendorff (2011). Social networks, job search methods and reservation wages: Evidence for Germany. International Journal of Manpower 32(7), 796-824.

Calvó-Armengol, A. and M. O. Jackson (2004). The effects of social networks on employment and inequality. American Economic Review 94(3), 426-454.

Calvó-Armengol, A. and M. O. Jackson (2007). Networks in labor markets: Wage and employment dynamics and inequality. Journal of Economic Theory 132(1), 27-46.

Calvó-Armengol, A., E. Patacchini, and Y. Zenou (2009). Peer effects and social networks in education. Review of Economic Studies 76(4), 1239-1267.

Cappellari, L. and K. Tatsiramos (2010). Friends networks and job finding rates. IZA Working Paper No. 5240.

Card, D. and L. Giuliano (2011). Peer effects and multiple equilibria in the risky behavior of friends. NBER Working Paper No. 17088.

Cingano, F. and A. Rosolia (2012). People I know: Job search and social networks. Journal of Labor Economics 30(2), 291-332.

Cipollone, P. and A. Rosolia (2007). Social interactions in high school: Lessons from an earthquake. American Economic Review 97(3), 948-965.

Dahl, G. B., K. V. Løken, and M. Mogstad (2012). Peer effects in program participation. NBER Working Paper No. 18198.

Damm, A. P. (2012). Neighborhood quality and labor market outcomes: Evidence from quasi-random neighborhood assignment of immigrants. Norface Migration Discussion Paper No. 2012-25.

DeGiorgi, G., M. Pellizzari, and S. Redaelli (2010). Identification of social interactions through partially overlapping peer groups. American Economic Journal: Applied Economics 2 (2), 241-275. 
Duflo, E. and E. Saez (2003). The role of information and social interactions in retirement plan decisions: Evidence from a randomized experiment. Quarterly Journal of Economics 118(3), 815-842.

Dustmann, C., A. Glitz, and U. Schönberg (2011). Referral-based job search networks. CReAM Discussion Paper No. 14/11.

Dustmann, C. and C. Meghir (2005). Wages, experience and seniority. Review of Economic Studies 72(1), 77108.

Edin, P.-A., P. Fredriksson, and O. Åslund (2003). Ethnic enclaves and the economic success of immigrants - evidence from a natural experiment. Quarterly Journal of Economics 118(1), 329-357.

Figlio, D. N., S. Hamersma, and J. Roth (2011). Information shocks and social networks. NBER Working Paper No. 16930.

Fitzenberger, B., A. Osikominu, and R. Völter (2006). Imputation rules to improve the education variable in the IAB employment subsample. Schmollers Jahrbuch : Journal of Applied Social Science Studies / Zeitschrift für Wirtschafts- und Sozialwissenschaften 126(3), 405-436.

Frijters, P., M. A. Shields, and S. W. Price (2005). Job search methods and their success: A comparison of immigrants and natives in the UK. Economic Journal 115(507), F359-F376.

Frölich, M. (2008). Parametric and nonparametric regression in the presence of endogenous control variables. International Statistical Review 76(2), 214227.

Galeotti, A. and L. P. Merlino (2010). Endogenous job contact networks. ISER Working Paper Series No. 2010-14.

Gartner, H. (2004). Die Imputation von Löhnen oberhalb der Beitragsbemessungsgrenze in der IAB-Beschäftigtenstatistik. IAB Working Paper.

Goel, D. and K. Lang (2010). Social ties and the job search of recent immigrants. CReAM Discussion Paper No. 22/10. 
Goyal, S. (2007). Connections: An Introduction to the Economics of Networks. Princeton University Press.

Granovetter, M. S. (1995). Getting a Job: A Study of Contacts and Careers (2 ed.). University of Chicago Press.

Guryan, J., K. Kroft, , and M. J. Notowidigdo (2009). Peer effects in the workplace: Evidence from random groupings in professional golf tournaments. American Economic Journal: Applied Economics 1(4), 3468.

Hellerstein, J., M. McInerney, and D. Neumark (2011). Neighbors and co-workers: The importance of residential labor market networks. Journal of Labor Economics 29(4), 659-695.

Hensvik, L. and O. N. Skans (2012). Social networks, employee selection and labor market outcomes: Toward an empirical analysis. Unpublished Manuscript.

Ioannides, Y. M. and L. D. Loury (2004). Job information networks, neighborhood effects, and inequality. Journal of Economic Literature 42(4), 1056-1093.

Jackson, M. O. (2008). Social and Economic Networks. Princeton: Princeton University Press.

Jacobson, L. S., R. J. LaLonde, and D. G. Sullivan (1993). Earnings losses of displaced workers. American Economic Review 83(4), 685-709.

Jenkins, S. P. and L. S. Osberg (2004). Nobody to play with? The implications of leisure coordination. In D. S. Hamermesh and G. A. Pfann (Eds.), The Economics of Time Use: Contributions to Economic Analysis, Volume 271, pp. 113-145. Amsterdam: Elsevier.

Kramarz, F. and O. N. Skans (2011). When strong ties are strong networks and youth labor market entry. IFAU Working Paper 2011:18.

Kugler, A. (2003). Employee referrals and efficiency wages. Labour Economics 10(5), 531-556. 
Lalive, R. and P. Parrotta (2011). Coworker interactions in labor supply. Unpublished Manuscript.

Laschever, R. (2009). The doughboys network: Social interactions and the employment of World War I veterans. Unpublished paper, Department of Economics, University of Illinois at Urbana-Champaign.

Liu, X., E. Patacchini, Y. Zenou, and L.-F. Lee (2012). Criminal networks: Who is the key player? CEPR Discussion Paper No. 8772.

Loury, L. D. (2006). Some contacts are more equal than others: Informal networks, job tenure, and wages. Journal of Labor Economics 24(2), 299-318.

Manski, C. F. (1993). Identification of endogenous social effects: The reflection problem. Review of Economic Studies 60(3), 531-542.

Marmaros, D. and B. Sacerdote (2002). Peer and social networks in job search. European Economic Review 46(4-5), 870-879.

Mas, A. and E. Moretti (2009). Peers at work. American Economic Review 99(1), $112-145$.

McPherson, M., L. Smith-Lovin, and J. M. Cook (2001). Birds of a feather: Homophily in social networks. Annual Review of Sociology 27, 415-439.

Moffitt, R. A. (2001). Policy interventions, low-level equilibria, and social interactions. In S. N. Durlauf and H. P. Young (Eds.), Social Dynamics, Chapter 3. MIT Press.

Montgomery, J. D. (1991). Social networks and labor-market outcomes: Toward an economic analysis. American Economic Review 81(5), 1407-1418.

Montgomery, J. D. (1992). Job search and network composition: Implications of the strength-of-weak-ties hypothesis. American Sociological Review 57(5), 586-596.

Munshi, K. (2003). Networks in the modern economy: Mexican migrants in the U.S. labor market. Quarterly Journal of Economics 118(2), 549-599.

Pellizzari, M. (2010). Do friends and relatives really help in getting a good job? Industrial and Labor Relations Review 63(3), 494-510. 
Schmieder, J. F., T. von Wachter, and S. Bender (2009). The long-term impact of job displacement in Germany during the 1982 recession on earnings, income, and employment. Columbia University, Department of Economics Discussion Paper No. 0910/07.

Schmutte, I. (2010). Job referral networks and the determination of earnings in local labor markets. US Census Bureau Center for Economic Studies Paper No. CES-WP-10-40.

Simon, C. J. and J. T. Warner (1992). Matchmaker, matchmaker: The effect of old boy networks on job match quality, earnings, and tenure. Journal of Labor Economics $10(3)$, 306-330.

Stutzer, A. and R. Lalive (2004). The role of social work norms in job searching and subjective well-being. Journal of the European Economic Association 2(4), 696-719.

Topa, G. (2001). Social interactions, local spillovers and unemployment. Review of Economic Studies 68(2), 261-295.

Topa, G. (2011). Labor markets and referrals. In J. Benhabib, A. Bisin, and M. O. Jackson (Eds.), Handbook of Social Economics (1 ed.), Volume 1, Chapter 22, pp. 1193-1221. Amsterdam: Elsevier North Holland.

van den Berg, G. J. (1994). The effects of changes of the job offer arrival rate on the duration of unemployment. Journal of Labor Economics 12(3), 478-498.

von Wachter, T., J. Song, and J. Manchester (2009). Long-term earnings losses due to mass layoffs during the 1982 recession: An analysis using U.S. administrative data from 1974 to 2004. Unpublished Manuscript.

Wahba, J. and Y. Zenou (2005). Density, social networks and job search methods: Theory and application to Egypt. Journal of Development Economics 78(2), 443-473.

Weber, A. and H. Mahringer (2008). Choice and success of job search methods. Empirical Economics 35(1), 153-78.

Weinberg, B., P. B. Reagan, and J. J. Yankow (2004). Do neighborhoods affect work behavior? Evidence from the NLSY79. Journal of Labor Economics 22(4), 891-924. 
Table 1: Summary Statistics - Worker Sample

Number

10,916

Share Foreign

Average Age

40.0

Share in

Hamburg

Cologne

Frankfurt

Munich

Share in

1995

1996

Educational Attainment

Share missing education

Share low education

Share medium education

Share high education

Industry

Agriculture

Construction

Manufacturing, low tech

Manufacturing, basic

Manufacturing, high tech

Communications, transport \& utilities

Wholesale

Retail

Prof., med. and business services

Education \& Welfare

0.8

Public administration

0.1

Other services

6.9

Note: The table reports descriptive statistics of the sample of male workers who become unemployed as the result of an establishment closure in the Hamburg, Cologne, Frankfurt and Munich metropolitan area in the years 1995/1996. The sample comprises 1,814 establishments with between 5 and 50 employees in the year of their closure. 
Table 2: Summary Statistics - Before and After the Establishment Closure

\begin{tabular}{|c|c|c|c|c|c|}
\hline & Mean & $\begin{array}{c}\text { Standard } \\
\text { Deviation }\end{array}$ & $\begin{array}{c}\text { 10th } \\
\text { Percentile }\end{array}$ & $\begin{array}{c}50 \text { th } \\
\text { Percentile }\end{array}$ & $\begin{array}{c}\text { 90th } \\
\text { Percentile }\end{array}$ \\
\hline \multicolumn{6}{|l|}{ Before closure } \\
\hline No. of coworkers (last 5 years) & 132.6 & 228.1 & 9 & 43 & 379 \\
\hline Share of coworkers working in $\mathrm{t}$ (in \%) & 58.4 & 18.0 & 35.1 & 60.0 & 79.1 \\
\hline Duration of cowork & 3.0 & 2.9 & 1 & 2 & 7 \\
\hline Overall work experience & 12.4 & 4.2 & 6 & 14 & 17 \\
\hline No. of establishments worked at & 3.5 & 2.0 & 1 & 3 & 6 \\
\hline Establishment tenure & 3.4 & 3.6 & 1 & 2 & 8 \\
\hline Tenure in closing establishment & 5.1 & 4.9 & 1 & 3 & 15 \\
\hline Last wage in closing establishment & 88.1 & 44.9 & 49.6 & 77.7 & 135.1 \\
\hline Last log wage in closing establishment & 4.37 & 0.47 & 3.90 & 4.35 & 4.91 \\
\hline No. of years working (last 5 years) & 4.4 & 1.0 & 3 & 5 & 5 \\
\hline No. of establishments worked at (last 5 years) & 2.1 & 1.0 & 1 & 2 & 3 \\
\hline Average establishment size (last 5 years) & 64.8 & 109.3 & 8.0 & 29.0 & 154.0 \\
\hline Annual wage growth (last 5 years) (in $\%$ ) & 26.7 & 1958.9 & -4.3 & 1.7 & 20.4 \\
\hline \multicolumn{6}{|l|}{ After closure } \\
\hline Share DW working in $t+1$ & 71.6 & 45.1 & 0 & 1 & 1 \\
\hline Wage in $t+1$ & 87.6 & 42.8 & 51.0 & 77.4 & 134.3 \\
\hline Log wage in $\mathrm{t}+1$ & 4.38 & 0.44 & 3.93 & 4.35 & 4.90 \\
\hline \multicolumn{6}{|l|}{ Instrumental variable } \\
\hline Share of coworkers in mass-layoffs (in \%) & 4.2 & 10.9 & 0.0 & 0.0 & 10.0 \\
\hline Residual share (establishment FE) (in \%) & 0.0 & 9.0 & -6.1 & -0.2 & 3.0 \\
\hline Residual share (establishment/education FE) (in \%) & 0.0 & 8.4 & -5.1 & -0.0 & 2.4 \\
\hline
\end{tabular}

Note: Sample comprises 10,916 displaced male workers who had coworkers who were not themselves displaced workers. The instrumental variable is the share of working former coworkers who, after separation, worked in a large establishment $(>50$ employees) and separated from that establishment as part of a mass-layoff. Statistics on the residual shares are obtained by regressing the instrument on the specified fixed effects and summarizing the residuals. 
Table 3: Employment and Wage Effects

\begin{tabular}{|c|c|c|c|c|c|c|}
\hline & (1) & (2) & (3) & (4) & (5) & (6) \\
\hline & \multicolumn{3}{|c|}{ Employment Probability } & \multicolumn{3}{|c|}{ Log Wages } \\
\hline & \multicolumn{2}{|c|}{ OLS } & IV & \multicolumn{2}{|c|}{ OLS } & IV \\
\hline Employment rate coworkers & $\begin{array}{c}0.073 * * \\
{[0.031]}\end{array}$ & $\begin{array}{c}0.051 \\
{[0.048]}\end{array}$ & $\begin{array}{c}0.753 * \\
{[0.387]}\end{array}$ & $\begin{array}{c}0.054 * * \\
{[0.023]}\end{array}$ & $\begin{array}{l}0.067 * \\
{[0.036]}\end{array}$ & $\begin{array}{c}0.174 \\
{[0.264]}\end{array}$ \\
\hline Log number of coworkers & $\begin{array}{c}0.002 \\
{[0.005]}\end{array}$ & $\begin{array}{c}0.004 \\
{[0.007]}\end{array}$ & $\begin{array}{c}-0.015 \\
{[0.013]}\end{array}$ & $\begin{array}{c}0.006 \\
{[0.004]}\end{array}$ & $\begin{array}{c}0.008 \\
{[0.005]}\end{array}$ & $\begin{array}{c}0.005 \\
{[0.009]}\end{array}$ \\
\hline Tenure in closing establishment & $\begin{array}{c}-0.001 \\
{[0.002]}\end{array}$ & $\begin{array}{c}-0.001 \\
{[0.002]}\end{array}$ & $\begin{array}{c}0.000 \\
{[0.002]}\end{array}$ & $\begin{array}{c}0.001 \\
{[0.001]}\end{array}$ & $\begin{array}{c}0.001 \\
{[0.001]}\end{array}$ & $\begin{array}{c}0.001 \\
{[0.001]}\end{array}$ \\
\hline No. of years working (last 5 years) & $\begin{array}{c}0.043 * * * \\
{[0.005]}\end{array}$ & $\begin{array}{c}0.040 * * * \\
{[0.006]}\end{array}$ & $\begin{array}{c}0.050 * * * \\
{[0.008]}\end{array}$ & $\begin{array}{c}0.009^{*} \\
{[0.005]}\end{array}$ & $\begin{array}{c}0.004 \\
{[0.005]}\end{array}$ & $\begin{array}{c}0.006 \\
{[0.007]}\end{array}$ \\
\hline Average establishment size (last 5 years) & $\begin{array}{c}0.000 \\
{[0.000]}\end{array}$ & $\begin{array}{c}0.000 \\
{[0.000]}\end{array}$ & $\begin{array}{c}0.000 \\
{[0.000]}\end{array}$ & $\begin{array}{c}0.000 \\
{[0.000]}\end{array}$ & $\begin{array}{c}0.000 \\
{[0.000]}\end{array}$ & $\begin{array}{c}0.000 \\
{[0.000]}\end{array}$ \\
\hline Annual wage growth (last 5 years) & $\begin{array}{c}-0.000 * * * \\
{[0.000]}\end{array}$ & $\begin{array}{c}-0.000 * * * \\
{[0.000]}\end{array}$ & $\begin{array}{c}-0.000 * * * \\
{[0.000]}\end{array}$ & $\begin{array}{c}-0.082 * * * \\
{[0.019]}\end{array}$ & $\begin{array}{c}-0.062 * * * \\
{[0.019]}\end{array}$ & $\begin{array}{c}-0.064 * * * \\
{[0.019]}\end{array}$ \\
\hline Log wage in closing establishment in 1995 & $\begin{array}{c}0.020 \\
{[0.012]}\end{array}$ & $\begin{array}{c}0.024 \\
{[0.016]}\end{array}$ & $\begin{array}{c}0.021 \\
{[0.016]}\end{array}$ & $\begin{array}{c}0.697 * * * \\
{[0.024]}\end{array}$ & $\begin{array}{c}0.666^{* * *} * \\
{[0.035]}\end{array}$ & $\begin{array}{c}0.666^{* * * *} \\
{[0.035]}\end{array}$ \\
\hline Average age coworkers & $\begin{array}{c}-0.002 \\
{[0.010]}\end{array}$ & $\begin{array}{c}-0.005 \\
{[0.012]}\end{array}$ & $\begin{array}{c}-0.005 \\
{[0.012]}\end{array}$ & $\begin{array}{c}0.003 \\
{[0.006]}\end{array}$ & $\begin{array}{c}0.021 * * * \\
{[0.008]}\end{array}$ & $\begin{array}{c}0.020 * * * \\
{[0.008]}\end{array}$ \\
\hline Average age coworkers squared & $\begin{array}{c}0.000 \\
{[0.000]}\end{array}$ & $\begin{array}{c}0.000 \\
{[0.000]}\end{array}$ & $\begin{array}{c}0.000 \\
{[0.000]}\end{array}$ & $\begin{array}{c}0.000 \\
{[0.000]}\end{array}$ & $\begin{array}{c}-0.000 * * * \\
{[0.000]}\end{array}$ & $\begin{array}{c}-0.000 * * \\
{[0.000]}\end{array}$ \\
\hline Share coworkers medium education & $\begin{array}{c}-0.011 \\
{[0.032]}\end{array}$ & $\begin{array}{c}0.010 \\
{[0.042]}\end{array}$ & $\begin{array}{c}-0.006 \\
{[0.043]}\end{array}$ & $\begin{array}{c}0.080 * * * \\
{[0.024]}\end{array}$ & $\begin{array}{c}0.028 \\
{[0.030]}\end{array}$ & $\begin{array}{c}0.025 \\
{[0.030]}\end{array}$ \\
\hline Share coworkers high education & $\begin{array}{c}-0.110 * \\
{[0.064]}\end{array}$ & $\begin{array}{l}-0.137 * \\
{[0.080]}\end{array}$ & $\begin{array}{l}-0.156^{*} \\
{[0.082]}\end{array}$ & $\begin{array}{c}0.203 * * * \\
{[0.055]}\end{array}$ & $\begin{array}{c}0.061 \\
{[0.063]}\end{array}$ & $\begin{array}{c}0.06 \\
{[0.063]}\end{array}$ \\
\hline Share female coworkers & $\begin{array}{c}-0.054 * \\
{[0.030]}\end{array}$ & $\begin{array}{c}-0.079 * * \\
{[0.037]}\end{array}$ & $\begin{array}{c}-0.074 * \\
{[0.038]}\end{array}$ & $\begin{array}{c}-0.011 \\
{[0.024]}\end{array}$ & $\begin{array}{c}-0.103^{* * *} * \\
{[0.029]}\end{array}$ & $\begin{array}{c}-0.102 \text { *** } \\
{[0.029]}\end{array}$ \\
\hline Share immigrant coworkers & $\begin{array}{c}-0.040 \\
{[0.041]}\end{array}$ & $\begin{array}{c}-0.044 \\
{[0.059]}\end{array}$ & $\begin{array}{c}0.059 \\
{[0.084]}\end{array}$ & $\begin{array}{c}-0.003 \\
{[0.031]}\end{array}$ & $\begin{array}{c}-0.041 \\
{[0.039]}\end{array}$ & $\begin{array}{c}-0.026 \\
{[0.053]}\end{array}$ \\
\hline Establishment fixed effects & & yes & yes & & yes & yes \\
\hline Observations & 10,916 & 10,661 & 10,659 & 7,789 & 7,435 & 7,433 \\
\hline Number of groups & & 1,559 & 1,558 & & 1,375 & 1,374 \\
\hline 1st stage statistics employment rate cowor & & & & & & \\
\hline Share coworkers in mass-layoffs & & & $\begin{array}{c}-0.131 * * * \\
{[0.016]}\end{array}$ & & & $\begin{array}{c}-0.138 * * * \\
{[0.021]}\end{array}$ \\
\hline F-stat 1st stage & & & 65.1 & & & 42.7 \\
\hline
\end{tabular}


Table 4: Robustness Checks Employment

\begin{tabular}{|c|c|c|c|c|c|c|c|}
\hline & (1) & (2) & (3) & (4) & (5) & (6) & (7) \\
\hline & $\begin{array}{l}\text { Establishment/ } \\
\text { Education } \\
\text { Fixed Effects }\end{array}$ & No Controls & $\begin{array}{l}\text { Using Mass- } \\
\text { layoffs in Medium } \\
\text { and Large } \\
\text { Establishments }\end{array}$ & $\begin{array}{c}\text { First Lag of } \\
\text { Mass-layoffs } \\
\text { Excluded }\end{array}$ & Wage Control & Competitors & $\begin{array}{c}\text { Network Size } \\
\text { Control }\end{array}$ \\
\hline Employment rate coworkers & $\begin{array}{c}\mathbf{0 . 6 5 8} \\
{[0.402]}\end{array}$ & $\begin{array}{l}0.644 * \\
{[0.379]}\end{array}$ & $\begin{array}{l}0.601 * * \\
{[0.260]}\end{array}$ & $\begin{array}{c}0.419 \\
{[0.462]}\end{array}$ & $\begin{array}{l}0.829 * \\
{[0.436]}\end{array}$ & $\begin{array}{c}\mathbf{0 . 6 7 7} \\
{[\mathbf{0 . 4 1 5}]}\end{array}$ & $\begin{array}{c}0.856 * * \\
{[0.417]}\end{array}$ \\
\hline Log number of coworkers & $\begin{array}{l}-0.012 \\
{[0.014]}\end{array}$ & $\begin{array}{l}-0.008 \\
{[0.015]}\end{array}$ & $\begin{array}{l}-0.011 \\
{[0.010]}\end{array}$ & $\begin{array}{l}-0.006 \\
{[0.015]}\end{array}$ & $\begin{array}{c}-0.007 \\
{[0.011]}\end{array}$ & $\begin{array}{l}-0.005 \\
{[0.015]}\end{array}$ & \\
\hline Average $\log$ wage coworkers in $t$ & & & & & $\begin{array}{l}-0.070 \\
{[0.048]}\end{array}$ & & \\
\hline Employment rate two-link away contacts & & & & & & $\begin{array}{c}-0.240 \\
{[0.452]}\end{array}$ & \\
\hline Log number two-link away contacts & & & & & & $\begin{array}{l}-0.005 \\
{[0.012]}\end{array}$ & \\
\hline Number of coworkers (in 1,000 ) & & & & & & & $\begin{array}{l}-0.101 \\
{[0.140]}\end{array}$ \\
\hline Number of coworkers (in 1,000) squared & & & & & & & $\begin{array}{c}0.082 \\
{[0.104]}\end{array}$ \\
\hline Observations & 10,007 & 10,659 & 10,659 & 10,652 & 10,502 & 10,642 & 10,659 \\
\hline Number of groups & 1,822 & 1,558 & 1,558 & 1,557 & 1,528 & 1,555 & 1,558 \\
\hline F-Stat/Kleibergen-Paap statistic 1st stage & 67.1 & 49.5 & 142.0 & 41.1 & 59.0 & 26.8 & 59.1 \\
\hline
\end{tabular}

Note: For a list of the additional control variables included (apart from column (2)), see Table 3, column (3). Apart from columns (3) and (4), the instrumental variable for the coworker employment rate is the share of working former coworkers who, after separation, worked in a large establishment ( $>50$ employees) and separated from that establishment as part of a mass-layoff. In column (1), a full set of establishment/education group fixed effects is included. In column (2), the only control variables included are the network size and a full set of establishment fixed effects. In column (3), the instrument is calculated for mass-layoffs in medium and large establishments (>10 employees). In column (4), masslayoffs that occurred in the year immediately prior to displacement have been excluded from the construction of the instrument. In column (5), the average wage of the coworkers in the network is included as an additional control variable. In column (6), the employment rate and log number of a displaced worker's two-link away contacts are included as additional control variables and the employment rate instrumented with the share of two-link away contacts who worked in a large establishment (>50 employees) and separated from that establishment as part of a mass-layoff. In column (7), actual numbers of coworkers (in 1,000) and their square are used rather than their log to control for the overall network size. Standard errors are robust and clustered at the closing establishment level. A $(*)$ denotes statistical significance at the $10 \%$ level, a (**) at the $5 \%$ level, and a $(* * *)$ at the $1 \%$ level. 
Table 5: Placebo Tests

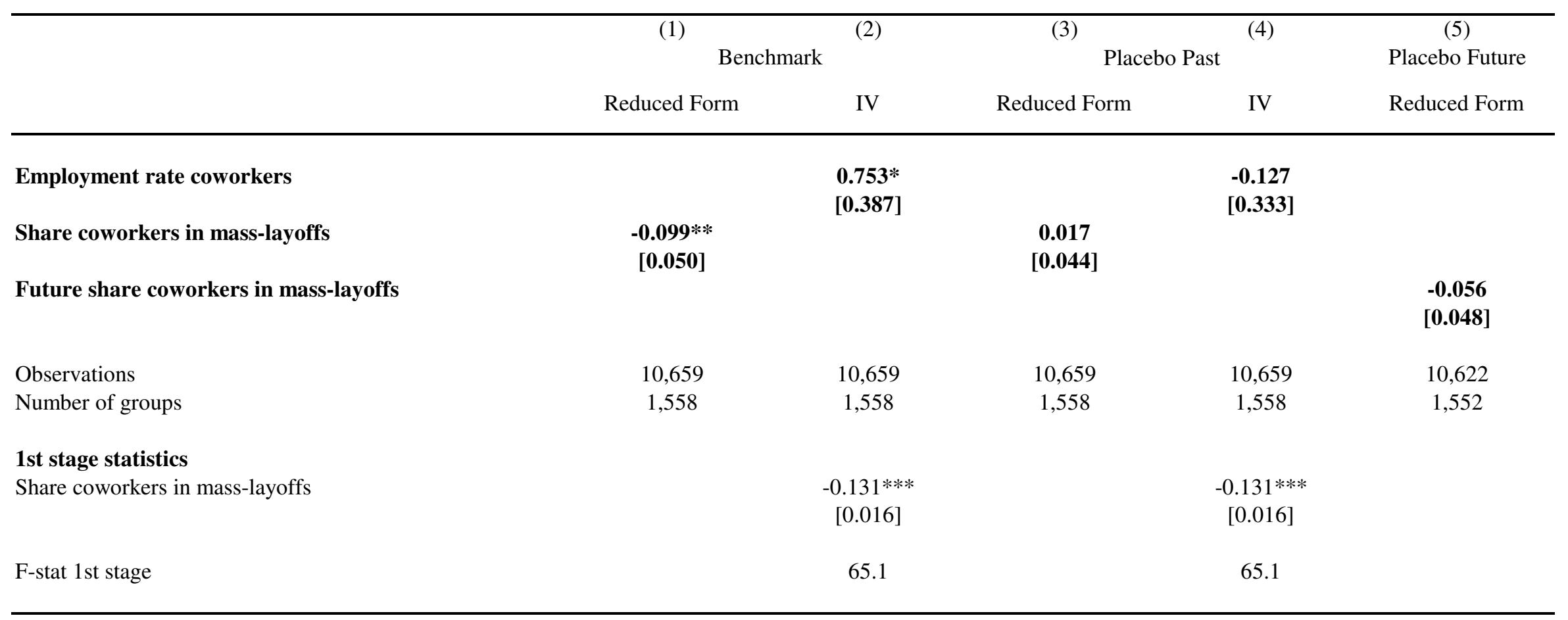

Note: The dependent variable in these estimations is the employment status in the year before the start of the network building phase, t- 6 (columns (3) and (4)), or the employment status in the year after displacement, $t+1$ (columns (1), (2) and (5)). Included control variables are the same as in Table 3, column (3). Columns (1) and (2) refer to the benchmark model (compare Table 3). The instrumental variable used in columns (2) and (4) for the coworker employment rate is the share of working former coworkers who, after separation, worked in a large establishment ( $>50$ employees) and separated from that establishment as part of a mass-layoff. Column (5) shows reduced form results using the future share of working former coworkers who worked in a large establishment ( $>50$ employees) and separated from that establishment as part of a mass-layoff between $\mathrm{t}+1$ and $\mathrm{t}+5$. Standard errors are robust and clustered at the closing establishment level. A (*) denotes statistical significance at the $10 \%$ level, a (**) at the $5 \%$ level, and a (***) at the $1 \%$ level. 
Table 6: Heterogeneity Demographic Subgroups

\begin{tabular}{|c|c|c|c|c|c|c|c|c|c|c|c|}
\hline & (1) & (2) & (3) & (4) & (5) & (6) & (7) & (8) & (9) & (10) & (11) \\
\hline & $\begin{array}{c}\text { Low } \\
\text { Education }\end{array}$ & $\begin{array}{l}\text { Medium } \\
\text { Education }\end{array}$ & $\begin{array}{c}\text { High } \\
\text { Education }\end{array}$ & German & Foreign & $\begin{array}{l}\text { Young } \\
(<=30)\end{array}$ & $\begin{array}{c}\text { Main (25- } \\
55)\end{array}$ & Old $(>=50)$ & $\begin{array}{c}\text { Small } \\
\text { Establishments } \\
\quad(<=10)\end{array}$ & $\begin{array}{c}\text { Medium } \\
\text { Establishments } \\
\quad(11-30)\end{array}$ & $\begin{array}{c}\text { Large } \\
\text { Establishments } \\
\quad(>30)\end{array}$ \\
\hline Employment rate coworkers & $\begin{array}{c}2.550 \\
{[1.640]}\end{array}$ & $\begin{array}{c}0.744 \\
{[0.492]}\end{array}$ & $\begin{array}{c}0.171 \\
{[0.944]}\end{array}$ & $\begin{array}{l}0.705^{*} \\
{[0.399]}\end{array}$ & $\begin{array}{c}2.335 \\
{[2.362]}\end{array}$ & $\begin{array}{l}1.567 * \\
{[0.883]}\end{array}$ & $\begin{array}{c}0.343 \\
{[0.406]}\end{array}$ & $\begin{array}{c}1.791 \\
{[1.549]}\end{array}$ & $\begin{array}{c}0.238 \\
{[0.606]}\end{array}$ & $\begin{array}{c}1.235 * * \\
{[0.561]}\end{array}$ & $\begin{array}{c}0.765 \\
{[1.716]}\end{array}$ \\
\hline Observations & 873 & 8,509 & 625 & 9,110 & 1,089 & 2,058 & 9,040 & 2,121 & 3,209 & 5,021 & 2,429 \\
\hline Number of groups & 253 & 1,387 & 182 & 1,429 & 305 & 629 & 1,493 & 533 & 838 & 591 & 129 \\
\hline F-stat 1st stage & 11.6 & 46.3 & 17.0 & 60.1 & 3.5 & 18.8 & 55.1 & 7.7 & 30.8 & 34.2 & 3.3 \\
\hline
\end{tabular}

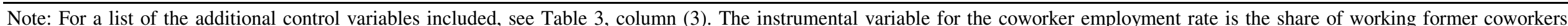

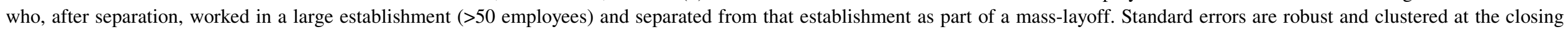
establishment level. A (*) denotes statistical significance at the $10 \%$ level, a $(* *)$ at the $5 \%$ level, and a $(* * *)$ at the $1 \%$ level. 
Table 7: Heterogeneity Across Information Providers (1)

\begin{tabular}{|c|c|c|c|c|}
\hline & $\begin{array}{c}\text { (1) } \\
\text { Age Cohort }\end{array}$ & $\begin{array}{c}(2) \\
\text { Gender }\end{array}$ & $\begin{array}{c}\text { (3) } \\
\text { Education }\end{array}$ & $\begin{array}{c}\text { (4) } \\
\text { Nationality }\end{array}$ \\
\hline ER - same characteristic & $\begin{array}{c}1.133 * * * \\
{[0.429]}\end{array}$ & $\begin{array}{l}0.629 * \\
{[0.371]}\end{array}$ & $\begin{array}{l}0.645^{*} \\
{[0.383]}\end{array}$ & $\begin{array}{l}0.668 * \\
{[0.386]}\end{array}$ \\
\hline ER - different characteristic & $\begin{array}{c}0.568 \\
{[0.391]}\end{array}$ & $\begin{array}{l}1.154 * \\
{[0.604]}\end{array}$ & $\begin{array}{l}1.031 * * \\
{[0.458]}\end{array}$ & $\begin{array}{l}0.974 * * \\
{[0.461]}\end{array}$ \\
\hline $\begin{array}{l}\text { Observations } \\
\text { Number of groups }\end{array}$ & $\begin{array}{c}10,659 \\
1,558\end{array}$ & $\begin{array}{c}10,659 \\
1,558\end{array}$ & $\begin{array}{c}10,659 \\
1,558\end{array}$ & $\begin{array}{c}10,659 \\
1,558\end{array}$ \\
\hline Kleibergen-Paap statistic 1 st stage & 33.3 & 36.0 & 32.1 & 32.0 \\
\hline P-value equality coefficients & 0.03 & 0.28 & 0.15 & 0.29 \\
\hline
\end{tabular}

Note: For a list of the additional control variables included, see Table 3, column (3). Group-specific employment rates are calculated by splitting the overall employment rate in a network E/NS into subcomponents S/NS and D/NS, where S and D are the number of employed workers in each subgroup, and $\mathrm{S}+\mathrm{D}=\mathrm{E}$. The instruments are constructed accordingly. In column (1), coworkers are distinguished by their age cohort, defined by +/- five years of the displaced worker's age. In column (2), coworkers are distinguished by their gender. In column (3), coworkers are distinguished by their education level, either without vocational training (or missing information), with vocational training, or with college education. In column (4), coworkers are distinguished by their citizenship status, either German or immigrant. Standard errors are robust and clustered at the closing establishment level. A $(*)$ denotes statistical significance at the $10 \%$ level, a (**) at the $5 \%$ level, and a $(* * *)$ at the $1 \%$ level. 
Table 8: Heterogeneity Across Information Providers (2)

(1)

Industry (3-digit)
(2)

(3)
(4)

Firm Size
ER - same industry

ER - different industry

0.384

[0.386]

$1.108 * *$

[0.486]

ER - same county

ER - different county

ER - above median duration

ER - below median duration

ER -above median firm size

ER - below median firm size

Observations

Number of groups

Kleibergen-Paap statistic 1st stage

$\mathrm{P}$-value equality coefficients
Contact Intensity

Geographic Proximity

Note: For a list of the additional control variables included, see Table 3, column (3). Group-specific employment rates are calculated by splitting the overall employment rate in a network E/NS into subcomponents S/NS and D/NS, where S and D are the number of employed workers in each subgroup, and $\mathrm{S}+\mathrm{D}=\mathrm{E}$. The instruments are constructed accordingly. In column (1), coworkers are distinguished by the three-digit industry they work in in $\mathrm{t}$ (or, for the unemployed former coworkers, the last three-digit industry they worked in). In column (2), coworkers are distinguished based on whether or not they work in the same county as the displaced worker in t (or, for the unemployed former coworkers, the last county they worked in). In column (3), coworkers are distinguished based on whether they worked strictly more or less than the median duration of joint employment spells with former coworkers in the sample. In column (4), coworkers are distinguished based on whether at the time of cowork with the displaced worker, they worked in an establishment that was strictly larger or smaller than the median establishment size in which the displaced worker experienced his joint employment spells. Standard errors are robust and clustered at the closing establishment level. A (*) denotes statistical significance at the $10 \%$ level, a $(* *)$ at the $5 \%$ level, and a $(* * *)$ at the $1 \%$ level. 
Table 9: Effects on Employment over Time

\begin{tabular}{|c|c|c|c|c|c|}
\hline & (1) & (2) & (3) & (4) & (5) \\
\hline & 1 year & 2 years & 3 years & 4 years & 5 years \\
\hline Employment rate coworkers & $\begin{array}{l}0.753 * \\
{[0.387]}\end{array}$ & $\begin{array}{c}-0.112 \\
{[0.383]}\end{array}$ & $\begin{array}{c}-0.049 \\
{[0.354]}\end{array}$ & $\begin{array}{c}-0.205 \\
{[0.342]}\end{array}$ & $\begin{array}{c}-0.124 \\
{[0.325]}\end{array}$ \\
\hline $\begin{array}{l}\text { Observations } \\
\text { Number of groups }\end{array}$ & & & $\begin{array}{c}10,659 \\
1,558\end{array}$ & & \\
\hline F-stat 1st stage & & & 65.1 & & \\
\hline
\end{tabular}

Note: For a list of the additional control variables included, see Table 3, column (3). 